\title{
Utility of Clinical Symptoms, Serology and Ultrasonographic Findings in the Diagnose of Hydatid Cyst of the Liver in Children
}

\author{
Sergey Viktorovich Minaev (iD) ${ }^{1,}$, Mikhail Alexandrovich Axelrov ${ }^{2}$, Alina Mashchenko (iD ${ }^{1}$ and Igor \\ Nikolaevich Gerasimenko ${ }^{1}$ \\ ${ }^{1}$ Department of Pediatric Surgery, Stavropol State Medical University, Stavropol, Russia \\ ${ }^{2}$ Department of Pediatric Surgery, Tyumen State Medical University, Tyumen, Russia \\ "Corresponding author: Department of Pediatric Surgery, Stavropol State Medical University, 310 Mira St., Stavropol, Russia. Tel: +79-624507653, Email: sminaev@yandex.ru
}

Received 2019 March 21; Revised 2019 August 20; Accepted 2019 August 31.

\section{Abstract}

Objectives: The aim of this study was to determine the effectiveness of various diagnostic methods of HCL in children.

Methods: From 2005 to 2019, we examined 154 children with suspected HCL. A total 93 (60.4\%) children had HCL, and 61 (39.6\%) had nonparasitic cysts. All children received clinical and laboratory examination with US. We divided patients with HCL into Group I (CL type of HCL, 27 patients), Group II (CE1 type, 32 patients), and Group III (CE2 type, 34 patients).

Results: Comprehensive examination, including clinical manifestations of disease together with US and ELISA, showed sensitivity of $59.8 \%$ and specificity of $47.5 \%$ for all types of HCL.

Conclusions: We found that the most informative diagnostic approach for all types of HCL in children is a combination of clinical manifestations together with US and ELISA.

Keywords: Hydatid Cyst, Echinococcosis, Ultrasonography, ELISA, Diagnostic, Children

\section{Background}

Various aspects of the diagnosis of hydatid cyst of the liver (HCL) remain relevant in pediatric practice (1). In the literature on children's specialties, there are very few studies on the specificity and sensitivity of different approaches to the diagnosis of HCL in children, according to the stage of the parasite's life cycle $(2,3)$. Unlike in adult practice where diagnostic algorithms are widely used, there are limited studies on the early diagnosis of HCL in pediatric practice (4).

\section{Objectives}

We sought to determine the effectiveness of various diagnostic methods of HCL in children, depending on the stage of parasitic activity.

\section{Methods}

From January 4, 2005 to December 28, 2018, a total 93 children were admitted with isolated form of HCL of type CL-CE2 and with cyst size $>2 \mathrm{~cm}$. There were 61 boys and 32 girls, with average age $9.1 \pm 1.8$ ( 3 - 17) years. Patients underwent clinical examination with laboratory diagnostics; serological testing using ELISA with an EchinococcusIgG-ELISA-BEST reagent kit (D-3356; VECTOR-BEST, Russia); and Doppler ultrasound (US) examination of the abdominal organs using an ARIETTA V60 device (Hitachi Aloka Medical Ltd., Japan) with four linear and convex transducers of 3.5 and $5 \mathrm{MHz}$. To interpret the US data, we used the international classification of ultrasound images of $\mathrm{HCL}$, approved by the World Health Organization for echinococcosis (5) (Figure 1). Patients were divided into groups, depending on the type of HCL: Group I (CL type) with 27 patients, Group II (CE1 type) with 32, and Group III (CE2 type) with 34 .

To determine the diagnostic value of clinical and laboratory follow-up, we included 61 patients with nonparasitic congenital and acquired cysts (comparison group).

Surgery and postoperative immunohistochemistry are definitive methods of determining the type of cyst. Surgical treatment was performed for all patients. Laparoscopic echinoccectomy with intraoperative evaluation of parasitic activity was performed in patients with HCL (6). A liver resection with cyst was performed in children with nonparasitic cysts.

The Ethics Committee of Stavropol State Medical Uni-

Copyright (C) 2019, Author(s). This is an open-access article distributed under the terms of the Creative Commons Attribution-NonCommercial 4.0 International License (http://creativecommons.org/licenses/by-nc/4.0/) which permits copy and redistribute the material just in noncommercial usages, provided the original work is properly cited. 


\section{TYPE OF CYST}
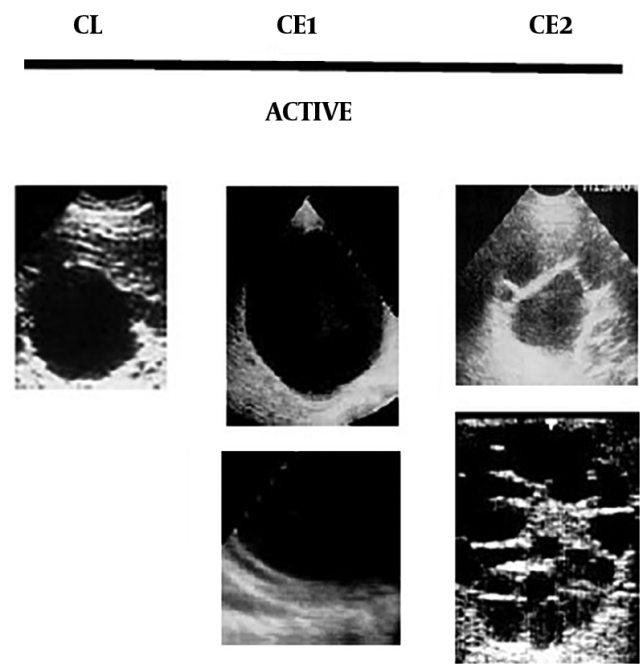

CE3

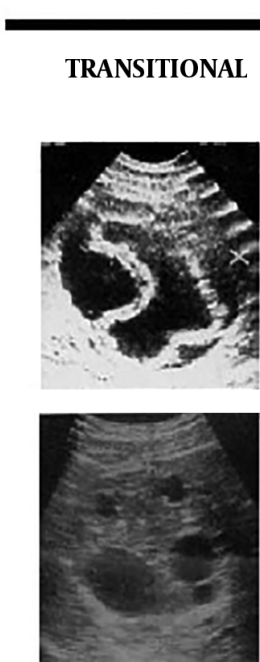

CE4

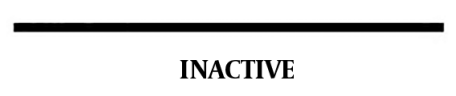

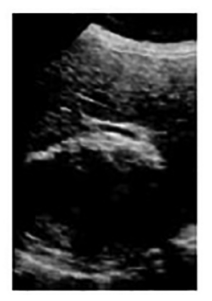

Figure 1. Types of HCL which be found on US examination (5)

versity approved the study, and informed consent was obtained from the parents of all patients, as their legal representatives.

We determined the coefficients of sensitivity (Se) and specificity (Sp) were determined (7). Clinical and laboratory follow-up are designated true positive (TP), false negative (FN), false positive (FP), and true negative (TN), and we calculated Se and Sp as follows:

$S e=\frac{T P}{T P+F N}$

$S p=\frac{T N}{T P+T N}$

The Student $t$-test and $\chi^{2}$ test were used for statistical analyses with Statistica V.10.0 (StatSoft, USA). A P value of $<$ 0.05 was considered to indicate statistical significance.

\section{Results}

When attending our clinic, patients had the following clinical signs: pain in the right hypochondrium, 64 (41.6\%) patients; enlarged liver, 59 (38.3\%); enlarged abdomen, 44 (28.6\%); loss of appetite, 37 (24.0\%); weakness, 32 (20.8\%); nausea, 23 (14.9\%); dry skin, 27 (17.5\%); pruritus, 31 (20.1\%); and sleep disturbance, 16 (10.4\%). Positive clinical criteria were considered one local sign or symptom together with one systemic sign or symptom. Evaluation of clinical manifestations of HCL showed $\mathrm{Se}=49.2 \%$ and $\mathrm{Sp}=27.6 \%$. All patients with CL-type cysts had a negative ELISA result; in patients with CE1,11(34.4\%) had a positive result; in those with CE2, 19 (55.9\%) patients had a positive ELISA result. Conducting ELISA in children with echinococcosis had a low diagnostic value $(\mathrm{Se}=16.4 \%$ and $\mathrm{Sp}=28.8 \%$ ). US with CL had high diagnostic value in 21 (77.7\%) children, 29 (90.6\%) with CE1, and 34 (100\%) with CE2. We found a high US success rate, with $\mathrm{Se}=91.1 \%$ and $\mathrm{Sp}=92.3 \%$ (Table 1 ).

In assessing the $\mathrm{Sp}$ and Se of a combined diagnostic method with different types of cysts, the indicators increased from CL to CE2 types. ELISA diagnostics showed Se $=30.2 \%$ and $\mathrm{Sp}=23.8 \%$. Clinical manifestations combined with US and ELISA yielded $\mathrm{Se}=59.8 \%$ and $\mathrm{Sp}=47.5 \%$.

In determining the $\mathrm{Sp}$ and Se of combined diagnostic methods (clinical manifestations with US and ELISA) for different types of HCL, we found that for CL-type cysts, these methods had $\mathrm{Se}=51.0 \%$ and $\mathrm{Sp}=53.6 \%$; for CE1 cysts, these values were $\mathrm{Se}=65.0 \%$ and $\mathrm{Sp}=69.2 \%$; for CE2-type cysts, these methods yielded $\mathrm{Se}=84.4 \%$ and $\mathrm{Sp}=89.3 \%$. The Sp and the Se of clinical manifestations together with US and ELISA for CE2-type cysts were significantly higher ( $P$ $<0.05)$ than the values for CL and CE1. An integrated approach can provide reliable detection of echinococcosis at any stage of the parasite's life cycle $\left(\chi^{2}=7.973, \mathrm{P}=0.019\right)$. The Sp and Se of both clinical manifestations and serol- 


\begin{tabular}{|c|c|c|c|c|c|}
\hline \multirow{2}{*}{ Parasite Stage $(N=93)$} & \multirow{2}{*}{$\begin{array}{l}\text { Clinical Manifestations } \\
\qquad \text { Abs (\%) }\end{array}$} & \multirow{2}{*}{$\begin{array}{c}\text { Ultrasound Imaging }{ }^{\mathbf{a}} \\
\text { Abs (\%) }\end{array}$} & \multirow{2}{*}{$\begin{array}{c}\text { ELISA } \\
\text { Abs (\%) }\end{array}$} & \multicolumn{2}{|c|}{ Reliability Index } \\
\hline & & & & $\chi^{2}$ & $\mathbf{P}$ \\
\hline$C L(n=27)$ & $10(37.0)$ & $21(77.7)$ & $0(0)$ & 21.306 & 0.00 \\
\hline $\operatorname{CE} 1(n=32)$ & $15(46.9)$ & $29(90.6)$ & $11(34.4)$ & 14.00 & 0.00 \\
\hline Total & $44(46.5)$ & $84(90.3)$ & $30(32.2)$ & 45.088 & 0.00 \\
\hline Sensitivity & $49.2 \%$ & $91.1 \%$ & $16.4 \%$ & & \\
\hline Specificity & $27.6 \%$ & $92.3 \%$ & $28.8 \%$ & & \\
\hline$\chi^{2}$ & 2.751 & 4.312 & 7.187 & & \\
\hline $\mathbf{P}$ & 0.253 & 0.116 & 0.028 & & \\
\hline
\end{tabular}

${ }^{\mathrm{a}}$ Coincident with intraoperative data.

ogy were statistically improved in patients with CE2-type lesions compared with CL and CE1, which did not show any increase in Sp and Se.

\section{Discussion}

Previous investigations (1) have emphasized that US is an effective method for visualizing HCL (Se $80 \%$ - 99\%, Sp $60 \%-97 \%$ ) with active cysts (CE2 - CE5). Serological methods for the diagnosis of HCL have a high Se (38\% - 93\%) and Sp (80\% - 100\%). A meta-analysis conducted by Iranian researchers of the incidence of echinococcosis, based on seropositivity, showed that $6.0 \%$ of the total population is infected and the above method is specific for HCL, with Sp 95.1\% (8). Previous authors have also identified US as the most sensitive method for diagnosing HCL of types CE3 CE5, with Se 97.6\% and Sp 99\%; these authors also emphasize that US is sensitive and specific for determining HCL types CL and CE1 - CE3 in children (6). In our work, the data obtained were comparable to the abovementioned studies. However, our results remain to be confirmed in integrated studies among children with HCL.

In summary, the effectiveness of HCL diagnosis in children with isolated and combined liver damage increased from CL to CE2 types. The most informative diagnostic method for all types of HCL is a comprehensive approach, taking into account clinical manifestations together with ELISA and US.

\section{Acknowledgments}

We thank Edanz Group (www.edanzediting.com/ac) for editing draft of this manuscript.

\section{Footnotes}

Authors' Contribution: All authors of this manuscript have directly participated in the planning, execution, or analysis of this study; drafting the article, conception and design, revising it: Sergey Viktorovich Minaev; analysis and interpretation of data, conception and design: Mikhail Alexandrovich Axelrov; drafting the article, analysis: Alina Mashchenko; analysis and interpretation of table: Igor Nikolaevich Gerasimenko.

Conflict of Interests: None of the authors has any conflict of interest.

Ethical Approval: The Ethics Committee approved the study (Board meeting N5 January 16, 2008).

Financial Disclosure: The authors have no financial interests related to the material in the manuscript.

Funding/Support: The authors don't have any Funding or Support.

Patient Consent: Informed consent was obtained from the parents of the patients, as their legal representatives.

\section{References}

1. Brunetti E, Tamarozzi F, Macpherson C, Filice C, Piontek MS, Kabaalioglu A, et al. Ultrasound and cystic echinococcosis. Ultrasound Int Open. 2018;4(3):E70-8. doi: 10.1055/a-0650-3807. [PubMed: 30364890]. [PubMed Central: PMC6199172].

2. Minaev SV, Razin M, Aksel'rov M, Aidemirov A, Shamsiev AM, Poluxov $\mathrm{R}$, et al. Hydatid cyst morbidity in endemic regions of the community of independent states: A multicenter study. Med News North Caucasus. 2018;13(3):453-8. doi: 10.14300/mnnc.2018.13076.

3. Toro A, Schembari E, Mattone E, Di Carlo I. Hydatid cyst of the liver: A challenge that can be amplified shifting from open to laparoscopic surgery. World JSurg. 2018;42(9):3054-5. doi:10.1007/s00268-018-44842. [PubMed: 29349486]. 
4. Brunetti E, Kern P, Vuitton DA; Writing Panel for the WHO-IWGE. Expert consensus for the diagnosis and treatment of cystic and alveolar echinococcosis in humans. Acta Trop. 2010;114(1):1-16. doi: 10.1016/j.actatropica.2009.11.001. [PubMed: 19931502].

5. Working Group WHO Informal. International classification of ultrasound images in cystic echinococcosis for application in clinical and field epidemiological settings. Acta Tropica. 2003;85(2):253-61. doi: 10.1016/s0001-706x(02)00223-1.

6. Minaev SV, Gerasimenko IN, Kirgizov IV, Shamsiev AM, Bykov NI, Shamsiev JA, et al. Laparoscopic treatment in children with hydatid cyst of the liver. World J Surg. 2017;41(12):3218-23. doi: 10.1007/s00268- 017-4129-x. [PubMed: 28752428].

7. Genders TS, Spronk S, Stijnen T, Steyerberg EW, Lesaffre E, Hunink MG Methods for calculating sensitivity and specificity of clustered data: A tutorial. Radiology. 2012;265(3):910-6. doi: 10.1148/radiol.12120509. [PubMed: 23093680].

8. Gholami S, Tanzifi A, Sharif M, Daryani A, Rahimi MT, Mirshafiee S, et al. Demographic aspects of human hydatidosis in Iranian general population based on serology: A systematic review and meta-analysis. Vet World. 2018;11(10):1385-96. doi: 10.14202/vetworld.2018.1385-1396. [PubMed: 30532491]. [PubMed Central: PMC6247888]. 